\title{
Isolated Adult Hypoganglionosis Resulting in Toxic Megacolon: A Case Report
}

\author{
Toksik Megakolona Yol Açan İole Yetișkin Hipoganglionozis: Bir Olgu Sunumu
}

\section{Șahin Kahramanca', Gülay Özgehan², Bahadır Rüçhan Celep³ ${ }^{3}$ Gaye Ebru Șeker², Ata Türker Arıkök4, Tevfik Küçükpınar²}

${ }^{1}$ General Surgery Clinics, Kars State Hospital, Kars, Turkey, ${ }^{2}$ General Surgery Clinics, Dışkapı Yuldirm Beyazıt Research and Training Hospital, Ankara, Turkey, ${ }^{3}$ Department of General Surgery, Afyon Kocatepe University Medical School, Afyon, Turkey, ${ }^{4}$ Pathology Clinics, Dişkeapr

Yildurm Beyazt Research and Training Hospital, Ankara, Turkey

\begin{abstract}
Isolated hypoganglionosis is a rare form of intestinal innervation defects. It is characterized by reduced number of myenteric ganglia and low acetyl cholinesterase activity in the lamina propria. Clinically, it resembles classical Hirschsprung's disease with severe constipation or even pseudo-obstruction. Here in, we report a case of isolated hypoganglionosis presenting with toxic megacolon.
\end{abstract}

Key words: adult; colonic pseudo-obstruction; Hirschsprung's disease; rectosigmoid aganglionosis

\section{ÖZET}

izole hipoganglionozis, intestinal inervasyon defektlerinin nadir sebeplerinden biridir. Lamina propriada düșük asetilkolinesteraz aktivitesi ve myenterik ganglion sayısında azalma ile karakterizedir. izole hipoganglionozis, ciddi kabızlık ve pseudo-obstrüksiyon kliniği ile klasik Hirschsprung hastalığına benzer. Biz bu yazıda toksik megakolon ile bașvuran izole hipoganglionozisi olan bir yetișkin hastayı sunuyoruz.

Anahtar kelimeler: yetișkin; kolonda yalancı tıkanma; Hischsprung hastalığı; rektosigmoid aganglionozisi

\section{Introduction}

The enteric nervous system is an intrinsic network of nerve cells and glias within the gastrointestinal wall. Intestinal dysganglionosis is a group of anomalies of the enteric nervous system including aganglionosis, hypoganglionosis, intestinal neuronal dysplasia (IND) and ganglioneuromatosis ${ }^{1}$.

Uzm. Dr. Sabin Kahramanca, Kars Devlet Hastanesi, Kars, Türkive,
Hypoganglionosis can be seen as an isolated form or associated with Hirschsprung's disease (HD) ${ }^{2}$. Hypoganglionosis as an isolated disease accounts for $5 \%$ of neuronal intestinal malformations ${ }^{3}$. The differential diagnosis of the entities is mainly based on histological, immunohistochemical and electron microscopy findings since their clinical features are similar ${ }^{4}$. Histologically, HD is defined as absence of intramural ganglia in the Meissner (submucosal) and Auerbach (myenteric) neural plexuses especially in the distal colon. IND is characterized by hyperganglionosis, giant ganglia and ectopic ganglia. In isolated hypoganglionosis $(\mathrm{IH})$, the number of ganglia per a centimeter of bowel's longitudinal axis is decreased and the distance between ganglia, as well as the plexus area, is increased ${ }^{4,5}$. There is very low or absent activity of acetyl cholinesterase (AchE) in the mucosa. These developmental anomalies are usually diagnosed in infancy or childhood, but there are studies reported in adults regarding these entities. Here, we report a case of IH in a 19 year-old male patient with sigmoid toxic megacolon.

\section{Case Presentation}

A 19 year-old male patient was admitted to our emergency department with abdominal pain, vomiting and diminished stool discharge for the last two days. He had xeroderma, aphasia, mental and growth retardation. He had severe abdominal distention, diminished bowel sounds and rebound tenderness on physical examination. The leukocyte count of $21600 / \mu$ l was the only remarkable laboratory test. Sigmoid colon was dilated with megacolon appearance on X-ray (Figure 1). 
We performed an emergency laparotomy and found that the left side of the colon, particularly the portion of the sigmoid colon above the recto-sigmoid flexure was severely dilated (Figure 2). We performed a sigmoidectomy and a Hartmann's procedure.

On postoperative 8th day, necrotic and fecaloid drainage was observed from the incision and the leukocyte count elevated subsequently. Based on the findings, we decided to perform a re-laparotomy. On abdominal exploration, there was about 1 liter of purulent material in the abdominal cavity. The rectal stump had necrotic parts and the the stitches on distal part

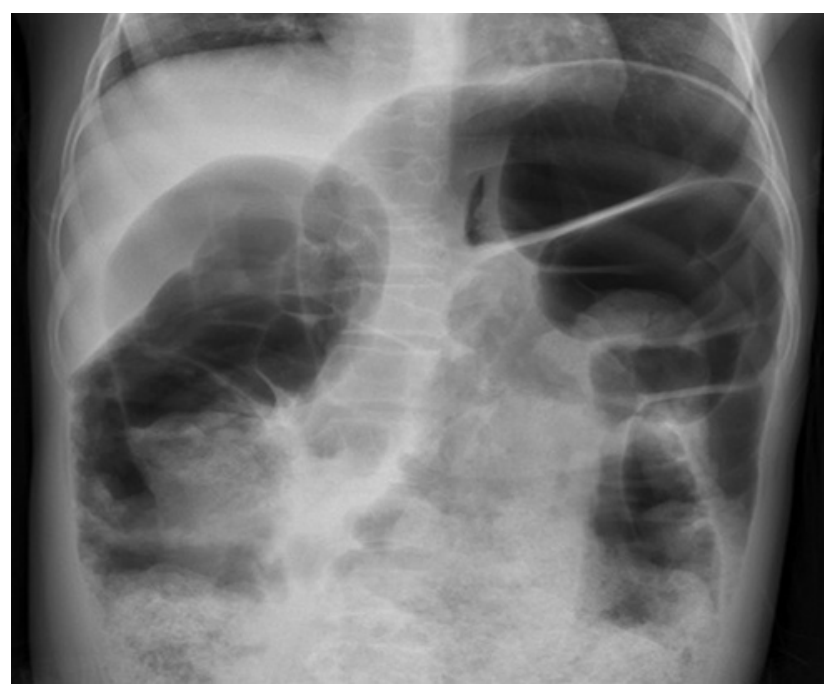

Figure 1. Sigmoid megacolon appearance on plain x-ray graph.

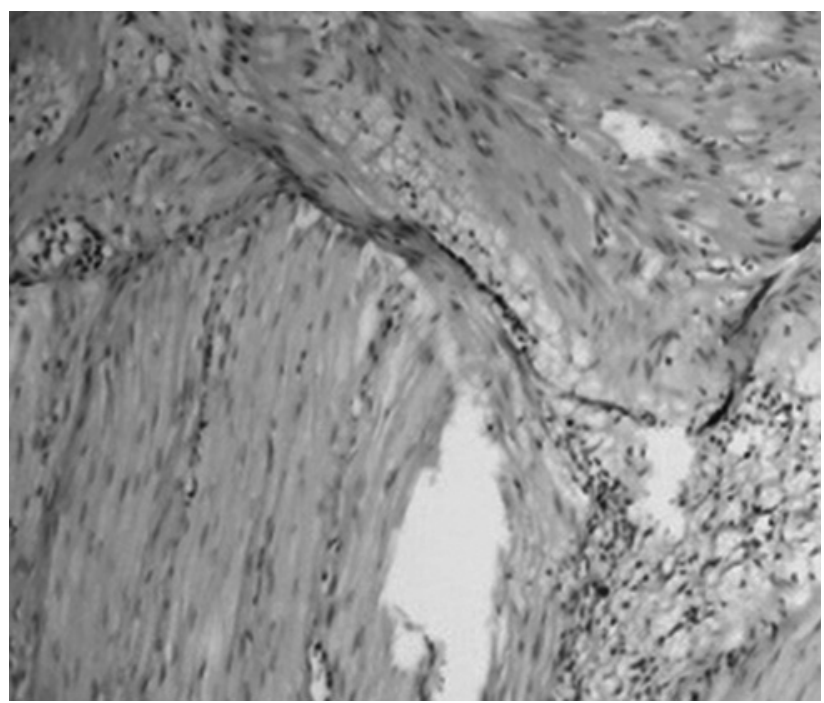

Figure 3. Focal hypoganglionosis with normal number of ganglia in myenteric plexus on proximal dilated segment (HEx200 optic). were not intact. We removed the necrotic sections of the rectum and closed the wound in two layers. The intra abdominal cavity was irrigated and aspirated with five liters of saline solution. Patient was discharged from our general surgery clinic at 21th day after re-laparotomy.

Histopathological examination revealed focal hypoganglionosis with normal number of ganglia in myenteric plexus on proximal dilated segment and scarce dysplastic ganglia on distal narrowed part (Figures 3 and 4). The number and the histology of the ganglia at both surgical margins were normal.

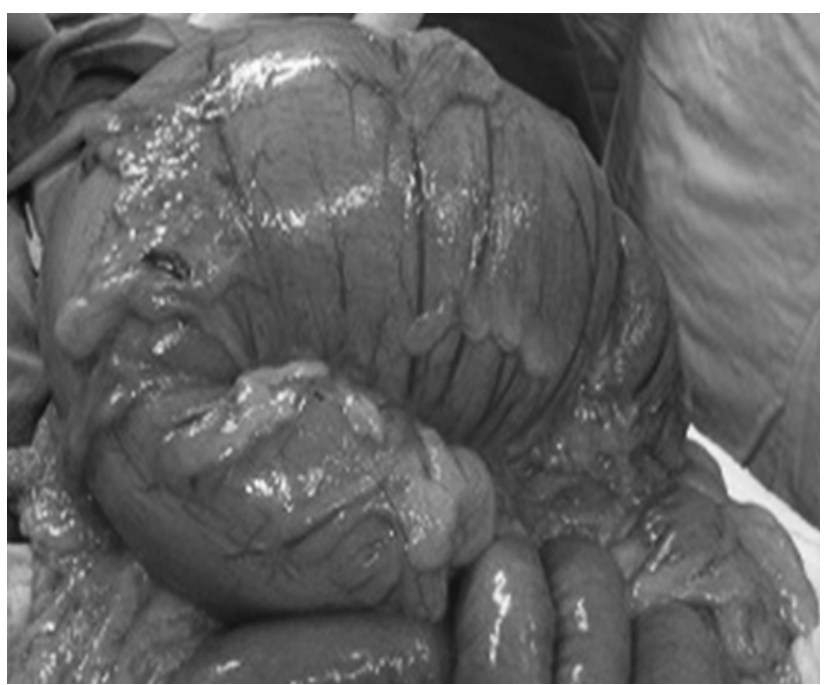

Figure 2. Intraoperative appearance of sigmoid megacolon.

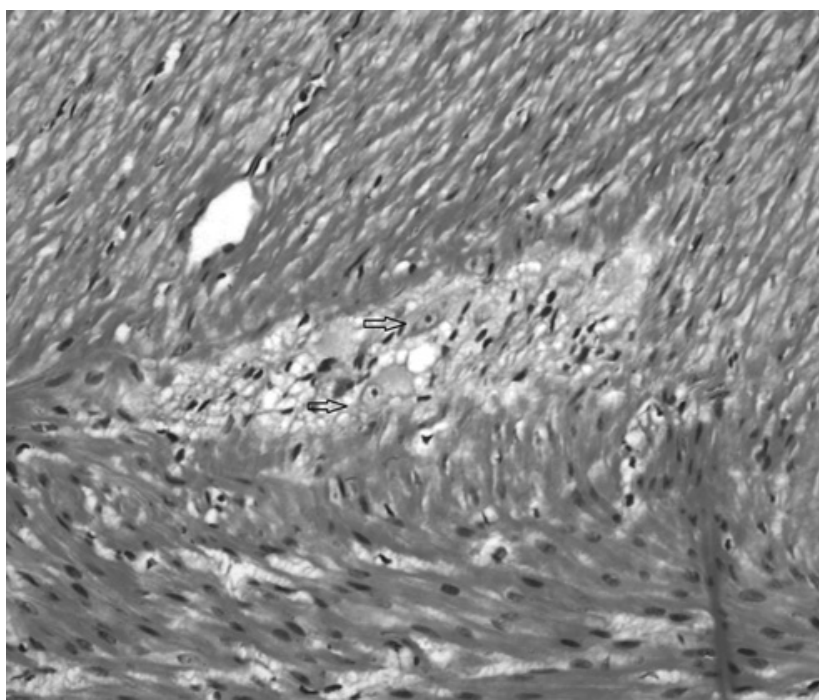

Figure 4. Scarce dysplastic ganglia on distal narrowed part (HEx200 optic). 


\section{Discussion}

Colonic pseudo-obstruction in adults which is characterized by obstructive symptoms without underlying mechanical reason is a challenging problem in emergency surgery. IH and adult-onset HP are rare causes of pseudo-obstruction ${ }^{2,6}$. In our case, emergency laparotomy was needed due to sigmoid toxic megacolon and the diagnosis was based on the postoperative histopathological examination.

To the best of our knowledge, this case is the third case of isolated hypoganglionosis presenting with sigmoid megacolon in an adult. Ito et al. and Qadir et al. presented the previous two cases $^{2,7}$.

The lack of distinct diagnostic criteria makes IH a controversial clinical entity. Although it may present as an isolated disorder, it may also be associated with HD and IND. IH can be differentiated by reduced number and size of myenteric ganglia, a low or absent AchE activity in the lamina propria, and hypertrophy of the muscularis mucosa and circular muscle. In HD, there is an absence of nerve cells in both submucosal and intramuscular layers of the distal colon ${ }^{3,5}$. Our patient had sparse dysplastic nerve cells in the myenteric plexus of the distal narrowed part of the removed specimen with normal ganglia at both proximal and distal margins. Do et al reported that IH was observed more frequently in females. However, the review conducted by Dingemann et al demonstrated a male to female ratio of $3: 1$ and $4: 1$ in isolated IH and HD, respectively ${ }^{3,6}$. Both studies reported that patients with $\mathrm{IH}$ were older than adultonset HD patients. The clinical features were similar in both diseases; however the duration of constipation was longer in adult-onset $\mathrm{HD}^{6}$.

Although there is no specific radiological finding to differentiate $\mathrm{IH}$ and $\mathrm{HD}$, the transition zone ratio at CT and double-contrast barium enema is higher in HD patients, meaning that adult-onset HD causes more dilatation ${ }^{8}$. Although alternative diagnostic tests like anorectal manometer and full-thickness bowel biopsies may be carried out, the histochemical staining is still the gold standard diagnostic test ${ }^{1}$.

In HD, there is an absence of ganglia in the submucosal and intramuscular layers. According to the criteria listed by $\mathrm{Li}$ and $\mathrm{Zhu}$, the number of myenteric ganglia per millimeter of colon tissue should be less than 1.52 in isolated $\mathrm{IH}^{9,10}$. Meier-Ruge demonstrated three findings for the diagnosis of IH: 1) the number of nerve cells was only $40 \%$ of the normally innervated colon; 2) the distance between ganglia was doubled; 3) the mean area of the ganglia was three times smaller than the normally innervated colon $^{11}$. Besides standard hematoxylin-eosin staining, immunohistochemical staining for AchE is also carried out to show low or absent activity; however the test can only be performed on frozen sections ${ }^{2}$. Thus, we could not use the test in our case. C-kit, ICC, silver, -100 staining may also be useful for diagnosis. The studies focusing on neural cell adhesion molecules and synaptophysin revealed that $\mathrm{IH}$ was a disorder of neuromuscular junction ${ }^{5}$.

Taguchi et al. proposed to classify IH into two groups: congenital and acquired IH. They reported that in congenital IH, the number and size of ganglia at birth are small, also called "hypogenesis", and though the size of ganglia increase by time, their numbers do not change. Acquired IH, with better prognosis after treatment, is seen at later years and associated with a degeneration of the ganglia due to ischemia, intramural inflammation or viral infection ${ }^{12}$.

Do et al. also classified IH patients in Korea into two groups as focal and diffuse $e^{6}$. They found that there is a focally narrowed transition zone in Type I with early onset and proposed a genetic or inflammatory cause. In Type II, the transitional zone was absent and there was a diffuse degenerative process along the colon. They thought that aging or prolonged laxative use as a result of transient constipation could play a role in the etiology of Type II IH.

The surgical treatment of the entity should focus on removing all hypoganglionic segments. In our case, we had to perform an urgent laparotomy and Hartmann procedure with a diagnosis toxic megacolon. The association of IH with the patient's unique findings of mental and growth retardation, aphasia and xeroderma raises the suspicion of an undefined syndrome, however in order to conclude we need more number of cases.

\section{Conclusion}

Sigmoid megacolon plays an important role in emergency surgery in adults. Although they are rare, $\mathrm{IH}$ and other adult onset intestinal dysganglionosis may be the underlying etiological factor. The operative treatment options depend on the extent and localization of the disease and the surgeon's preference. 


\section{References}

1. Montedonico S, Caceres P, Munoz N, et al. Histochemical staining for intestinal dysganglionosis: over 30 years experience with more than 1, 500 biopsies. Pediatr Surg Int 2011;27:479-86.

2. Qadir I, Salick MM, Barakzai A, et al. Isolated adult hypoganglionosis presenting as sigmoid volvulus: a case report. J Med Case Rep 2011;5:445.

3. Dingemann J, Puri P. Isolated hypoganglionosis: systematic review of a rare intestinal innervation defect. Pediatr Surg Int 2010;26:1111-5.

4. Puri P, Gosemann JH. Variants of Hirschsprung's disease. Semin Pediatr Surg 2012;21:310-8.

5. Zhang HY, Feng JX, Huang L, et al. Diagnosis and surgical treatment of isolated hypoganglionosis. World J Pediatr 2008;4:295-300.

6. Do MY, Myung SJ, Park HJ, et al. Novel classification and pathogenetic analysis of hypoganglionosis and adult-onset Hirschsprung's disease. Dig Dis Sci 2011;56:1818-27.
7. Ito T, Kimura T, Yagami T, et al. Megacolon in an adult case of hypoganglionosis, a pseudo-hirschsprung's disease: an autopsy study. Intern Med 2008;47:421-5.

8. Kim HJ, Kim AY, Lee CW, et al. Hirschsprung disease and hypoganglionosis in adults: radiologic findings and differentiation. Radiology 2008;247:428-34.

9. Li NP, Wu RL, Zhou S. Investigation on the pathological morphology of intestinal neuronal dysplasia. Chin J Pediatr Surg 2000;21:221-2.

10. Zhu XM, Gu ZC, Wang XD. The morphometric study of myenteric plexus of colon in children with hypoganglionosis. Chin J Pediatr Surg 2005;26:536-9.

11. Meier-Ruge WA, Brunner LA, Engert J, et al. A correlative morphometric and clinical investigation of hypoganglionosis of the colon in children. Eur J Pediatr Surg 1999;9:67-74.

12. Taguchi T, Masumoto K, Ieiri S, et al. New classification of hypoganglionosis: congenital and acquired hypoganglionosis. J Pediatr Surg 2006;41:2046-51. 